\section{Grand Prix de la Fondation de la Maison de la Chimie-Call for Nominations}

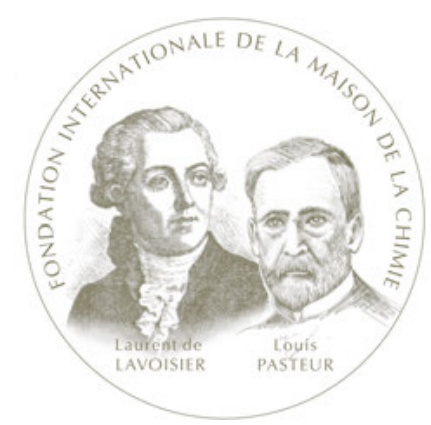

$\mathrm{T}$ he prize is meant to honor an original work in chemistry of benefit to mankind, society or nature. The Grand Prix will be awarded for the seventeenth time in 2020, to one or several persons, irrespective of nationality, and does carry a monetary award of 35,000 Euros.

All entries must imperatively be presented through a learned society or a national or international scientific organisation without any direct link with the nominee.

Entry forms, together with a report detailing the arguments for the nomination, must be returned to the Fondation de la Maison de la Chimie by 30 April 2020 by e-mail to presidence@maisondelachimie.com.

https://actions.maisondelachimie.com/les-prix-de-la-fondation/grandprix-de-la-fondation/

\section{DSM Bright Science Award 2020 in materials sciences-Call for Nominations}

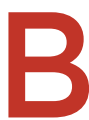
estowed in partnership with IUPAC, DSM invites nominations for the DSM Bright Science Award 2020 in materials sciences which is accompanied by a cash prize of $€ 25000$. This prestigious award has been established to recognize and reward experienced scientists, in the midst of their career, who have already made an indelible, positive impact on our global society and on the advancement of science in their respective field of research-and who we would like to stimulate to continue doing so by recognizing and rewarding their talent and achievements.
Scientists from all parts of the world who have made major contributions to fundamental or applied research in the field of materials sciences can be nominated for the award. A prime requirement is that the candidate's research must have significantly advanced the world's understanding and knowledge of key questions in this field. Candidates for the award can be put forward by nomination only.

Nomination deadline 1 February 2020.

An international judging committee will review the nominations and select the winner. The judging committee comprises members from DSM, DSM's Scientific Advisory Board, IUPAC, and a previous prize winner. It is a requirement of the award that the recipient will be present at the award ceremony, scheduled during the IUPAC-MACRO conference (5-9 July 2020, JeJu Island, South Korea) to receive the award personally and to deliver a lecture on their research work.

https://iupac.org/dsm-bright-science-award-2020-in-materials-sciencescall-for-nominations/

\section{0-International Year of Plant Health}

$\mathrm{T}$ he United Nations has declared 2020 as the International Year of Plant Health (IYPH). The year is a once in a lifetime opportunity to raise global awareness on how protecting plant health can help end hunger, reduce poverty, protect the environment, and boost economic

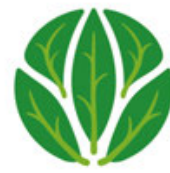

INTERNATIONAL YEAR OF PLANT HEALTH

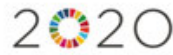
development.

The actual UN declaration makes clear connection with the 2030 Agenda for Sustainable Development; see more at https://undocs.org/A/RES/73/252;

If, as a chemist, you thought there will be no reason to celebrate in 2020 , think again!

http://www.fao.org/plant-health-2020 